\title{
TINGKAT PENDAPATAN DAN SEBARAN TENAGA KERJA \\ INDONESIA (TKI) BERDASARKAN NEGARA TUJUAN, STUDI \\ DI DESA ARYOJEDING KABUPATEN TULUNGAGUNG
}

\author{
Singgih Susilo \\ Universitas Negeri Malang \\ E-mail: $\underline{\text { singgih.susilo.fis@um.ac.id }}$
}

\begin{abstract}
Abstrak:Studi inibertujuan untuk mengetahui tingkat pendidikan dan pendapatan berdasarkan negara tujuan tempat TKI bekerja. Penelitian dilakukan di desa Aryojeding Kecamatan Rejotangan Kabupaten Tulungagung.Penelitian ini merupakan penelitian deskriptif kuantitatif.Pengambilan data mengunggunakan teknik wawancara terstruktur, dengan jumlah sampel 94 responden.Analisis data menggunakan tabulasi tunggal yang bertujuan untuk mengetahui karakteristik dari variable yang menjadi model.Hasil penelitian menunjukkan bahwa penyebaran Negara tujuan TKI dari desa Aryojeding sebagian besar bekerja di Negara Taiwan, sedangkan Negara tujuan yang kurang diminati oleh masyarakat Aryojeding adalah Negara tujuan Arab Saudi.Apabila dilihat dari tingkat pendapatan yang dikirim ke desa Aryojeding,terbesar terjadi pada kisaran Rp.3.000.000 hingga Rp. 4.000.000 setiap bulannya.TKI yang mengirim pendapatannya diatas Rp. 5 juta tergolang banyak (19\%). Tingkat pendidikan TKI di luar negeri paling tinggi adalahSLTA. Pada tingkat pendidikan SLTA, banyak yang bekerja di Korea Selatan dan Taiwan.Kesimpulan penelitian ini adalah bahwa adalah penyebaran negara tujuan masyarakat Aryojeding yang menjadi TKI, sebagian besar bekerja di Negara Taiwan, denganalasan karena negara tersebut memiliki perlindungan terhadap tenaga kerja asing dan perlindungan terhadap wanita. TKI wanita merasa aman untuk bekerja di Negara tersebut, disamping itu negara tersebut memilikistandar gaji yang tinggi.
\end{abstract}

Kata Kunci : Penyebaran Negara Tujuan, Pendidikan, Pendapatan, TKI.

\section{PENDAHULUAN}

Masalah ketenagakerjaan diakibatkan pencari kerja lebih banyak disbanding kesempatan kerja yang ada, akibatnya terjadi pengangguran. Terbatasnya kesempatan kerja di Indonesia, salah satunya menyebabkan sebagian tenaga kerja bekerja di luar negeri, menjadi Tenaga Kerja Indonesia (TKI). Rendahnya penyerapan tenaga kerja di dalam negeri terutama bagi wanita secara umum terjadi karena ketimpangan pasar tenaga kerja, yakni pencari kerja lebih untuk mencari dan memanfaatkan kesempatan kerja di luar negeri. Para wanita yang memanfaatkan kesempatan kerja di luar negeri ini disebut sebagai Tenaga Kerja Wanita (TKI).Setiap TKI memiliki alasan atau faktor pendorong yang melatarbelakangi keputusan mereka untuk bekerja ke luar negeri yang berbeda antara individu satu dengan yang lainnya. 
Singgih Susilo. Tingkat Pendapatan dan Sebaran Tenaga Kerja Indonesia (TKI)

Berdasarkan Negara Tujuan, Studi Di Desa Aryojeding Kabupaten Tulungagung

Model yang bisa digunakan untuk menjelaskan dan menganalisa migrasi TKI yang bekerja di luar negeri adalah model dorong-tarik atau push-pull theoryyang dikemukakan oleh Lee (1975). Menurut teori ini ada 4 faktor yang mendorong orang mengambil keputusan untuk bermobilitas yaitu: (a) Faktor-faktor yang terdapat di daerah asal (dorong), (b)Faktor-faktor yang terdapat di daerah tujuan (tarik),(c) Faktor penghalang, dan (d) Faktor pribadi. Teori migrasi lainnya yang populer terutama di negara berkembang, adalah teori migrasi berantai. Pada dasarnya teori ini menerangkan tentang proses pengambilan keputusan seseorang untuk meninggalkan kampung halaman yang dikaitkan dengan keberadaan famili atau kawan yang ada di daerah tujuan. Teori ini dapat menjelaskan migrasi luar negeri, terutama pada negara-negara tujuan di sekitar Indonesia, seperti Malaysia, Singapura, dan Brunai Darussalam. Banyaknya migrasi internasional illegal di Malaysia, tidak terlepas dari peran famili atau kawan yang mendahuluinya tinggal di negara tujuan tersebut.

Teori lain Fuller (1980), mengemukakan ada 5 tahap yang harus diperhatikansebelum menentukan sikap untuk bermigrasi atau tidak, Munculnya masalah karena pengaruh individu atau lingkungan (1) Inventarisasi solusi (2) Pengelompokan solusi (3) menjadi solusi local (4)Pengambilan keputusan (5)Tindakan yang diambil berdasarkan keputusan akan menetap atau bermigrasi. Fenomena ini terus berkembang seiring dengan perkembangan pola hubungan yang terjalin antar negara, baik dalam kontekss politik, ekonomi, maupun sosial budaya. Migrasi Internasional yang semakin tinggi merupakan salah satu sisi positif sebagai akibat terbukanya isolasi sosial, budaya, ekonomi, dan politik global yang saling bersinggungan (Junaidi,2007). Fenomena mobilitas tenaga kerja Indonesia yang bekerja di luar negeri diakui selain dapat membantu memecahkan masalah ketenaga kerjaan di Indonesia dan meningkatkan devisa negara, secara khusus juga dapat untuk memperbaiki nasib dan membangun diri TKI dan rumah tangganya di daerah asal.

Migrasi internasional tenaga kerja Indonesia dapat diartikan sebagai tenaga kerja yang meninggalkan sementara negaranya pindah ke negara lain dengan tujuan mencari penghasilan, meningkatkan status sosial ekonomi, pada saat tertentu kembali ke daerah asalnya dengan membawa terutama uang 
(remitansi) atau pada saat tertentu mengirimkan uang ke daerah asalnya, dan kembali lagi ke negara tujuan. Dengan kata lain, migrasi luar negeri merupakan usaha tenaga kerja Indonesia untuk meningkatkan status sosial ekonomi di daerah asal, dengan cara meninggalkan Indonesia sementara untuk bekerja di luar negeri (negara tujuan).

Fenomena tenaga kerja yang bekerja diluar negeri, telah lama terjadi di Kabupaten Tulungagung, berdasarkan data untuk tenaga kerja wanita mengalami peningkatan setiap tahunnya. Dilihat dari data yang dihimpun dari Dinsosnakertrans mulai tahun 2010 hingga tahun 2013 yakni, 2.135 orang yang berangkat dari tahun 2010, mengalami peningkatan pada tahun 2013 mencapai jumlah 2.925 orang (BPS Tulungagung, 2014).

Tenaga kerja luar negeri umumnya bekerja pada sektor non formal, seperti menjadi pembantu rumah tangga.Hal ini memberikan peluang yang besar pada wanita yang memiliki pendidikan menengah atau rendah untuk bekerja di luar negeri.Tenaga kerja wanita dari Kabupaten Tulungagung yang bekerja diberbagai Negara tujuan, fenomenanya mengarah pada negara dengan standar gaji yang tergolong tinggi. Selain itu,
Negara tersebut telah menerapkan perlindungan tenaga kerja dan perlindungan bagi wanita. Negara tersebut antara lain adalah Taiwan dan Hongkong.

\section{METODE}

Penelitian ini merupakansurvey dengan menggunakan pendekatan kuantitatif, yakni suatu penelitian yang datanya berdasar pada angka-angka (Arikunto, 2010). Tujuan penelitian ini untuk mengetahui sebaran TKI berdasarkan Negara tujuan, tingkat pendapatan, dan tingkat pendidikan TKI. Subjek dalam penelitian ini adalah seluruh TKI yang sedang bekerja di luar negeri atau TKI yang sementara ini ada dirumah, tetapi masih ada keinginan untuk kembali bekerja di luar negeri. Populasi TKI dan yang pernah menjadi TKI sebanyak 148 responden, diambil sebesar 60 persen sebagai sampel responden.yakni sebanyak 94 responden.

Penentuan sampel menggunakan metode simple random sampling yakni suatu tehnik pengambilan sampel menggunakan sitem acak sederhana. Lokasi yang dipilih adalah Desa Aryojeding.Penentuan Desa Aryojeding diambil secara purposive(disengaja) dengan pertimbanganbahwa penduduk 
Singgih Susilo. Tingkat Pendapatan dan Sebaran Tenaga Kerja Indonesia (TKI)

Berdasarkan Negara Tujuan, Studi Di Desa Aryojeding Kabupaten Tulungagung

desa Aryojeding banyak yang menjadi

TKI, sehingga Desa Aryojeding sering disebut desa TKI.

Instrumen yang digunakan adalah lembar kuesioner dengan teknik pengumpulan data berupa observasi, wawancara dan dokumentasi.Tehnik pengambilan data menggunakan wawancara terstruktur, yakni suatu wawancara yang dibantu menggunakan daftar pertanyaan (Quesioner).Data yang diambil adalah data primer dan data sekunder. Data primer diambil langsung dari responden yang menjadi TKI maupun keluarga yang pernah menjadi TKI luar negeri. Sedangkan data sekunder merupakan data yang diambil dari intansi terkait.Analisis dalam penelitian ini adalah analisis tabulasi tunggal yang tujuannya untuk mengetahui karakteristik tingkat pendidikan TKI, tingkat pendapatan yang dikirimkan TKI, dan sebaran negara tujuan tempat TKI bekerja.

\section{HASIL PENELITIAN DAN \\ PEMBAHASAN}

\section{Tingkat Pendidikan}

Kondisi pendidikan dalam penelitian ini merupakan jenjang pendidikan yan ditempuh oleh masyarakat yang diukur dengan menggunakan indikator pendidikan yang ditamatkan. Kondisi pendidikan ini erat kaitannya dengan ketrampilan yang dimiliki oleh TKI agar bisa bekerja dengan baik saat di luar negeri Tingkat pendidikan diukur berdasarkan pendidikan formal yang ditamatkan oleh responden. Tingkat pendidikan digolongkan menjadi 3 yaitu: SD, SMP, dan tamat SMA. Indikator pendidikan ini penting karena dengan pendidikan bisa mencerdaskan seseorang. Untuk mengetahui hasil penelitian tentang tingkat pendidikan responden dapat dilihat pada tabel berikut ini.

Tabel.1. Jumlah dan Persentase Responden menurut Tingkat Pendidikan Tahun 2014

\begin{tabular}{llll}
\hline No & Tingkat Pendidikan & Jumlah & Persentase \\
\hline 1 & SD & 11 & 11,7 \\
2 & SLTP & 25 & 26,6 \\
3 & SLTA & 58 & 67,7 \\
\hline Jumlah & & 94 & 100,0 \\
\hline
\end{tabular}


Berdasarkan hasil penelitian, diketahuibahwa sebagian besar responden berpendidikan tamatSLTAyakni sebanyak 67,7\%, dengan kata lain lebih dari separuh TKI desa Aryojeding yang bekerja di luar negeri umumnya memiliki tingkat pendidikan SLTA.

Dengan modal pendidikan tergolong menengah ini, TKIdapat dengan mudah untuk menyesuaikan bahasa maupun budaya negara tujuan.Banyaknya TKI yang berpendidikan menengah atas ini umumnya bekerja di Korea, Taiwan, Hongkong, dan Singapura. Hasil penelitian juga menunjukkan bahwa ada TKI yang berpendidikan SD, walaupun hanya sedikit jumlahnya (11,7 persen). TKI ini, yang sebagian besar wanita, bekerja di NegaraMalaysia dan Arab Saudi.

Tenaga kerja Indonesia yang berpendidikan SLTP sebesar 26,6 persen. Jumlah ini tergolong banyak, umumnya mereka yang bekerja di negara Malaysia, Arab Saudi dan Hongkong.TKI yang berpendidikan SLTP ini ternyata tidak ada yang bekerja di Negara Korea Selatan.Hal ini dikarenakan memang persyaratan untuk bekerja sebagai TKI di Korea Selatan, minimal harus berpendidikan SLTA.
Hasil penelitian terkait dengan tingkat pendidikan TKI di desa Aryojeding ini cukup menggembirakan karena lebih dari separoh TKI berpendidikan SLTA dan tergolong pendidikan menengah. Seperti diketahui, pada umumnya tingkat pendidikan masyarakat di daerah pedesaan masih tergolong rendah, dan masih menjadi kendala dalam kaitannya dengan kemampuan Sumber Daya Manusia yang sampai kini masih belum bisa teratasi. Muhajir (2010) dalam hasil survey UNESCO tahun 2004 tentang kualitas pendidikan di dunia, menunjukkan bahwa Indonesia berada pada peringkat ke 114 dari sekitar 175 negara di dunia. Hal ini memang sangat memprihatinkan namun inilah kenyataan yang harusdihadapi.

Selain itu rendahnya tingkat pendidikan di kalangan penduduk wanita di pedesaan adalah adanya alasan masyarakat tidak mau menyekolahkan anak perempuannya ke jenjang yang lebih tinggi, karena wanita hanya akan menjadi ibu rumah tangga. Namun pada masyarakat desa Aryojeding tidak berlakuanggapan tersebut karena sudah banyak wanita yang memiliki pendidikan tinggi.

Pendidikan yang tinggi diharapkan juga memberikan modalmoral yang tinggi 
pada masing-masing TKI saat bekerja di luar negeri. Dalam berita di media cetak maupunelektronik sering dijumpai kasus penganiayaan terhadap TKI karena TKI tersebut kurang berkomunikasi, kurang sopan terhadap majikannya, atau dengan sengaja menggoda suami majikannya. Kasus-kasus penyimpangan yang terjadi pada TKIantara lain bahwa dia tidak hanya menjadi pembantu rumah tangga, namun juga menjajakan diri pada pria hidung belang,atau bahkan kasus lesbian yang menimpa antar TKI. Jika masingmasing TKImemiliki pendidikan moral yang tinggi tentunya hal-hal tersebut tidak akan terjadi mengingat tujuan utama bekerja di luar negeri adalah bekerja.

\section{Tingkat Pendapatan}

Salah satu alasan TKI desa Aryojeding bekerja di luar negeri adalah untuk memperoleh pendapatan yang lebih tinggi dibanding dengan penghasilan yang diperoleh di dalam negeri. Pendapatan dalam penelitian ini adalah penghasilan TKI yang dikirim ke keluarganya di desa Aryojeding. Besar-kecilnya pendapatan yang dikirim sangat tergantung dengan penghasilan yang diperoleh TKI di Negara
Tujuan.Pendapatan yang mereka peroleh tentunya berbeda-beda, tergantung di negara mana TKI bekerja, karena masingmasing negara memiliki standar gaji untuk tenaga kerja Indonesia.Pendapatan yang dikirim oleh TKI ke daerah asal, dalam penelitian ini dikelompokkan menjadi 5 kelompok yaitu kurang dari Rp. 2.000.000 per bulan, (2) Rp. 2.000.000 - Rp. 3000.000;

Rp.3000.000- < Rp 4.000.000; (4)Rp.4000.000-Rp.5000.000; dan (5) > Rp.5000.000,-.

Untuk mengetahui tingkat pendapatan yang dikirim oleh TKI ke keluarganya di desa Aryojeding dapat dikaji pada table 2 . 
Tabel 2. Jumlah dan Persentase Responden Menurut Pendapatan yang Dikirim oleh TKI ke Desa Aryojeding, tahun 2014

\begin{tabular}{lll}
\hline Pendapatan & Frekuensi & $\%$ \\
\hline Rp. $<2.000 .000$ & 6 & 6,4 \\
Rp.2.000.000 - <Rp.3000.000 & 9 & 9,6 \\
Rp.3000.000 - <Rp.4.000.000 & 34 & 36,2 \\
Rp.4.000.000 - < Rp.5.000.000 & 26 & 27,6 \\
$>$ Rp.5.000.000 & 19 & 20,2 \\
\hline Jumlah & 94 & 100
\end{tabular}

Dari tabel 2 dapat dijelaskan bahwa sebagian besar TKI mengirimkan pendapatannya ke keluarganya di desa Aryojeding antara $\mathrm{Rp} 3$ juta hingga kurang dari $\operatorname{Rp} 4$ juta setiap bulannya, yaitu sebanyak 36,2 persen. Tingkat pendapatan TKI yang dikirim ke keluarganya paling sedikit terjadi pada pengiriman pendapatan kurang dari Rp.2000.000 yakni hanya sebasar 6,4 persen. Hasil penelitian ini menunjukkan bahwa TKI yangmengirim kurang dari Rp. 2000.000 per bulan dikirim oleh TKI yang bekerja di Negara Malaysia.Apabila dilihat dari standar gaji luar negeri, Negara Malaysia mempunyai standar gaji paling rendah jika dibanding dengan negara-negara lain seperti Singapura, Taiwan, Hongkong dan Korea Selatan.

Menarik untuk dikaji adalah pada pengiriman pendapatan ke keluarganya di desa Aryojeding pada pengiriman penghasilan diatas Rp.5.000.000. setiap bulannya, yakni sebanyak 20,2 persen.Besarnya jumlah pengiriman ini ternyata memberikan dampak positif terhadap kesejahteraankeluarga TKI di desa Aryojeding. Keadaan ini terjadi pada bapak Ahmad,yang menjadi TKI di Korea Selatan. Bapak Ahmad bekerja pada industry sparepartperusahaan mobil Hundai. Menurut bapak Ahmad, setiap bulannya bisa menerima gaji hamper setara dengan Rp. 8 juta.Bapak Ahmad ketika dua tahun yang lalu untuk berangkat menjadi TKI di Korea Selatan harus membayar uang sebesar Rp. 52 juta. Selama dua tahun ini Bapak Ahmad sudah memiliki rumah tergolong mewah, sebuah mobil Kijang Inova, dan memiliki usaha perikanan ikan Lele sebanyak tiga kolam.

Penghasilan yang dikirim ke keluarganya di desa Aryojeding antara Rp.4000.000 hinggakurang Rp.5.000.000 
Singgih Susilo. Tingkat Pendapatan dan Sebaran Tenaga Kerja Indonesia (TKI) Berdasarkan Negara Tujuan, Studi Di Desa Aryojeding Kabupaten Tulungagung

per bulannya, adalah sebesar 27,6 persen.

Berdasarkan Negara tempat bekerja TKI, menunjukkan besarnya penghasilan yang dikirim oleh TKI ini sangat bervariasi ada TKI yang bekerja di Taiwan, Negara Hongkong, Malaysia, Singapura maupun TKI yang bekerja di Negara Taiwan. Secara keseluruhan besarnya pendapatan yang dikirim ke desa Aryojeding sebesar 84 persen TKI mengirim uang ke keluarganya diatas Rp. 3.000.000,- . Penghasilan ini tergolong besar, jika dibandingkan dengan keluarga lain yang tidak menjadi TKI atau keluarga yang bekerja di sekitar desa Aryojeding.

Perbedaan pendapatan yang dikirimkantersebut berbeda dan bisa dilihat dari negara tujuan TKI bekerja.TKI yang bekerja di Negara Taiwan, gaji normal yang mereka terima sekitar Rp. 6.000 .000 per bulan, Hongkong Rp. 5.000.000 per bulan, Singapura Rp. 3.000 .000 per bulan sedangkan Malaysia Rp. 2.000.000 per bulan. Permasalahannya tidak selalu TKI yang bekerja di luar negeri menerima gaji penuh karena ada sebagian TKI, terutama tenaga kerja wanita (TKI) banyak yang proses keberangkatan menjadi TKI luar negeri melalui sistem potong gaji. Gaji mereka umumnyadipotong antara 8 atau
9 bulan, tergantung kesepakatan antara TKI dengan PJTKI setempat.

\section{Sebaran Negara Tujuan}

Negara tujuan TKIdari desa Aryojeding cukup bervariasi, mulai dari Negara Taiwan sampai pada Negara Arab Saudi.Namun yang menarik, pada umumnya sebagian besar mereka pernah menjadi TKI di Negara Malaysia. Banyaknya TKI yang bekerja di luar negeri tidak terlepas dari kemudahan untuk bisa bekerja di luar negeri. Banyaknya TKI dari desa Aryojeding yang sudah bekerja di luar negeri juga menjadi salah satu modal mudahnya memperoleh informasi untuk bekerja di luar negeri.

Adanya kantor PJTKI yang ada di desa Aryojeding, merupakan salah satu yang dapat membantu untuk menjadi TKI di luar negeri. Adanya pihak-pihak yang bisa membantu untuk bekerja di luar negeri, merupakan salah satu faktor pendorong minat masyarakat desa Aryojeding untuk bekerja di luar negeri.Hasil penelitian sebaran TKI berdasarkan negera tujuan, dapat diketahui pada tabel3. Dari tabel tersebut dapatdijelaskan bahwa TKI di desa Aryojeding banyak yang bekerja di Negara Taiwan, yakni mencapai 33 
persen, sedangkan negera tujuan yang TKI desa Aryojeding adalah Negara Arab paling sedikit sebagai tempat bekerja Saudi yakni hanya sebesar 2,1 persen.

Tabel 3. Sebaran TKI berdasarkan Negara Tujuan, Tahun 2014

\begin{tabular}{llll}
\hline No & Negara tujuan & Jumlah & Persentase \\
\hline 1 & Taiwan & 31 & 33 \\
2 & Hongkong & 19 & 20 \\
3 & Malaysia & 17 & 18 \\
4 & Korea Selatan & 11 & 11 \\
5 & Brunai Darussalam & 8 & 8.5 \\
6 & Singapura & 6 & 6.4 \\
7 & Arab Saudi & 2 & 2,1 \\
\hline Jumlah & & 94 & 100 \\
\hline
\end{tabular}

Menarik untuk dikaji bahwa TKI dari desa Aryojeding yang bekerja di Negara Hongkong tergolong besar, yakni sebesar 20 persen, setelah Negara Taiwan. TKI desa Aryojeding yang bekerja di Negara Korea selatan tergolong banyak yakni sebesar 12 persen, Negara tujuan Korea Selatan sebagai tempat bekerja TKI desa Aryojeding masih dibawah Negara Hongkong, Malaysia dan Taiwan, pada hal memiliki standar gaji yang lebih tinggi dibanding standar gaji Taiwan maupun Hongkong. Untuk bisa bekerja di Korea selatan memiliki persyaratan yang ketat, karena umumnya bekerja di pabrik, bukan bekerja di sector rumahtangga seperti di Hongkong maupun Taiwan.Biaya mahal yang dibutuhkan untuk bekerja di Korea
Selatan menjadi kendala tersendiri bagi masyarakat desa Aryojeding.

Dari data tersebut justru menunjukkan Negara Negara tujuan non Islam justru menjadi tujuan utama tempat bekerja TKI dari desa Aryojeding, pada hal awal awal masyarakat desa Aryojeding mengenal bekerja di luar negeri sebagai besar tujuannya adalah Negara Malaysia. Pada waktu Malaysia sebagai Negara tempat bekerja dari masyarakat Aryojeding sangat beralasan, disamping secara geografi merupakan Negara tetangga (dekat), juga factor budaya dan bahasa yang hamper sama dengan masyarakat Indonesia pada umumnya.

Perkembangan TKI di desa Aryojeding, rupanya ada keunikan dalam hal pilihan Negara tujuan sebagai tempat 
bekerja. Ada suatu fenomena pilihan negara tertentu dalam beberapa tahun terakhir ini.Hasil penelitian menunjukkan ada pilihan TKI baru dari TKI desa Aryojeding, yaitu Negara Taiwan sebagai tempat bekerja. Seandainya pilihan TKI desa Aryojeding berdasar pada tiga faktor penarik (gaji tinggi, jaminan perlindungan tenaga kerja, jaminan hak perlindungan kaum wanita), pertanyaanya mengapa tidak memilih Negara Hongkong yang juga memiliki tiga faktor penarik yang hampir sama. Pilihan tempat bekerja di Negara Taiwan bagi TKI baru Desa Aryojeding, merupakan fenomena keunikan tersendiri.

Negara Taiwan merupakan pilihan utama sebagai tempat bekerja dibanding negara tujuan lain.Standar gaji yang diperoleh memang Negara Taiwan lebih tinggi dibanding Negara Hongkong dan Singapura, yaknisebesar Rp. 6.000 .000 setiap bulannya, sedangkan standar gaji di Negara Hongkong hanya sebesar 5.000 .000 setiap bulannya.

Apabila melihat sejarah awal masyarakat mengenal bekerja di luar negeri, Negara Malaysia adalah tujuan utama.Sampai dengan tahun 2005, Malaysia merupakan Negara yang paling banyak dipilih oleh TKI yang berasal dari desa Aryojeding(Susilo, 2002). Lebih lanjut penelitian tersebut menemukan fakta, bahwa TKI desa Aryojeding memilih Negara Malaysia sebagai tempat bekerja, karena ada faktor yang melatarbelakangi, antara lainkarena Malaysia yang dianggap dekat jaraknya, Negara Malaysia dapat dimasuki oleh TKI illegal, serta banyaknya TKI sebelumnya yang telah bekerja di Negara tersebut.Orang pertama dari desa Aryojeding yang bekerja di luar negeri adalah bapak Suradi. Bapak Suradi bekerja sebagai TKI di Malaysia pada tahun 1978, ketika masih berumur 18 tahun, setelah sebelumya Bapak Suradi bekerja di daerah Sumatera sebagai tukang bangunan.

\section{KESIMPULAN}

Hasil penelitian ini memberikan kesimpulan bahwa TKI di desa Aryojeding sebagian besar atau lebih dari separoh berpendidikan SLTA, dan TKI yang berpenddikan SD jumlahnya sangat sedikit. Jumlah pendapatan TKI di Negara tujuan yang dikirim ke keluarganya di desa Aryojeding sebagian besar antara Rp.3.000.000 sampai dengan kurang Rp. 4000.000, dan jumlah pengiriman pendapatan diatas Rp. 5 juta tergolong banyak.TKI yang mengirim uang sejumlah lebih dari Rp.5 juta per 
bulannya uamumnya TKI yang bekerja di Negara Korea Selatan dan Negara Taiwan.Sebaran Negara tujuan bagi TKI desa Aryojeding sebagian besar bekerja di Negara Taiwan, terutama bagi TKI wanita atau TKW.TKI yang bekerja di negara Taiwan memiliki standar gaji yang cukup tinggi, serta ada perlindungan Negara bagi tenaga kerja asing dan bagi tenaga kerja wanita. Negara Taiwan menjadi pilihan masyarakat Aryojeding karena persyaratan tidak ketat, seperti yang terjadi untuk menjadi TKI di Korea Selatan.

\section{DAFTAR PUSTAKA}

Arikunto, Suharsimi. 2006. Prosedur Penelitian (Suatu Pendekatan Praktik). Jakarta: Rineka Cipta.

Badan Pusat Statistik. 2014. Tulungagung Dalam Angka 2013. Tulungagung: BPS Tulungagung.

Disnakertrans. 2014. Data Jumlah TKI Berangkat 2013. Tulungagung: Disnakertrans Tulungagung.

Fuller, Garry (eds.), 1980.Urbanization in Developing Nations, Center of Policy Studies, One Dag Hammarkjoid Plaza. New York, USA.

Junaidi. 2007. Mobilitas Penduduk dan Remitansisi.Diakses tanggal 25 Desember 2009.

Lee, Everett S. 1975. Suatu Teori Migrasi. Seri Terjemahan No. 3 Yogyakarta: Pusat Penelitian Studi Kependudukan Universitas Gajah Mada.
Mantra.1994. Mobilitas Sirkuler dan Pembangunan di Daerah Asal. Warta Demografi.

Muhajir. 2010. Ilmu Pendidikan Perspektif Kontekstual. Jogjakarta: Ar-Ruzz Media.

Susilo, 2002. Hubungan Antara Remitansi dengan Tingkat Kesejahteraan Keluarga pada TKI di Dukuh Dungmanten, Kabupaten Tulungagung,Surabaya: Pasca Sarjana UNAIR (Tesis). 